\title{
A CONSTRUCIÓN DO DISCURSO ACERCA DA LINGUA GALEGA NA PRENSA ESCRITA DE ÁMBITO ESTATAL. ANÁLISE DE EL PAÍS, EL MUNDO E ABC DURANTE A «ERA AZNAR» (1996-2004) \\ Paula Bouzas Rosende Georg-August-Universität Göttingen



CAstro, O. / M. LiÑEIRA (eds.) (2015): Trama e urda. Contribucións multidisciplinares desde os estudos galegos, Santiago de Compostela, Consello da Cultura Galega. doi:10.17075/tucmeg.2015.

\section{INTRODUCIÓN}

A prensa escrita segue a desempeñar na nosa sociedade un importante papel na creación e difusión de determinados discursos: non só chega a un importante número de persoas, senón que ademais funciona como institución recoñecida, responsable de informar e ofrecer interpretacións do que acontece. Neste proceso de mediación institucionalizada entre a realidade e os individuos, os medios hexemónicos tenderán a protexer a pervivencia do sistema social vixente (Martín Serrano 2004: 88, 135). A análise do discurso periodístico, xa que logo, será unha ferramenta que nos permitirá achegarnos ás estratexias que explican o mantemento ou a mudanza de determinadas estruturas sociais.

O presente artigo intégrase nun proxecto máis amplo, a través do que se pretende describir o discurso en torno ás linguas peninsulares distintas do español na prensa escrita de ámbito estatal dende a transición ata a actualidade. O obxectivo último será o de determinar as prácticas discursivas, sobre todo no plano lingüístico, que funcionan ideoloxicamente favorecendo determinadas percepcións e interpretacións.

A análise que se ofrece a continuación, no entanto, céntrase especificamente no galego e ten carácter sincrónico: limítase a un período temporal determinado, que abrangue as dúas lexislaturas nas que foi presidente do goberno español José María Aznar (1996-2004). O feito de que Aznar fose investido co apoio das principais formacións dos gobernos de Cataluña e Euskadi, entre outras, motiva unha serie de mudanzas nas políticas autonómicas e, polo tanto, na relación entre as autonomías e o estado, tema que cobra especial relevancia no debate público desta época. Dado que a cuestión lingüística constitúe un factor importante nesta dialéctica, as linguas pasan a formar parte esencial do discurso político transmitido en grande medida a través dos medios. O obxectivo desta contribución será describir a imaxe das linguas que se reflicte na prensa escrita hexemónica e os recursos lingüísticos que caracterizan o discurso en torno a elas. 
CAStro, O. / M. LiÑEIRA (eds.) (2015): Trama e urda. Contribucións multidisciplinares desde os estudos galegos, Santiago de Compostela, Consello da Cultura Galega. doi:10.17075/tucmeg.2015.

\section{MARCO TEÓRICO, METODOLOXÍA E CONCEPTOS PRINCIPAIS}

O marco teórico escollido é o da Análise Crítica do Discurso, que se centra no estudo sistemático das relacións entre o texto e o seu contexto social, isto é, as súas condicións sociais, as ideoloxías e as relacións de poder (Fairclough 1993). Parte, entre outros, do principio de que todo uso da linguaxe é unha práctica social na que existe unha relación dialéctica: cultura e sociedade están determinadas e configuradas polo discurso e, ao mesmo tempo, constitúen o discurso e danlle sentido (Titscher/Meyer/Wodak/Vetter 2000: 146). Nesta relación dialéctica, o papel da prensa é determinante: a través dela transmítense determinados puntos de vista, establécense esquemas categorizadores da realidade e constrúense ou perpetúanse determinados prexuízos (van Dijk 1987: 202-203).

Co termo «discurso» farase referencia á estrutura abstracta que transcende calquera conxunto de textos relacionados entre si por un criterio de contido, neste caso o tratamento das linguas ibéricas non estatais (Busse/Teubert 1994: 14); o termo «ideoloxía», pola súa banda, será empregado para significar un sistema de ideas que, sobre todo no ámbito social, político e relixioso, son compartidas por un grupo e determinantes na configuración das propias crenzas individuais (van Dijk 2003: 15, 20-21).

Como marco metodolóxico, escoulleuse o modelo múltiple de análise DIMEAN, que integra en diferentes niveis as perspectivas lingüística, social e pragmática e permite ser adaptado consonte os obxectivos de investigacións concretas (Warnke/Spitzmüller 2008: 23-43). Tendo en conta que o obxectivo deste traballo é unha descrición do discurso nun plano formal (isto é, orientada ás estruturas lingüísticas que o conforman), deixáronse a un lado aspectos máis contextuais, sen dúbida relevantes para a análise do discurso, como a caracterización dos axentes participantes no acto comunicativo e a intertextualidade (van Dijk 2003; Spieß 2008; Warnke/Spitzmüller 2008: 2032). Na análise, da que se ofrecerá unha síntese neste capítulo, tivéronse en conta os seguintes aspectos:

\begin{tabular}{|l|l|}
\hline Presentación & Titulares, entradas, tipo de texto. \\
\hline Macroestrutura semántica & $\begin{array}{l}\text { Temas recorrentes. } \\
\text { Esquemas ou superestruturas presupostas (tópoi). } \\
\text { Selección de información. }\end{array}$ \\
\hline Estrutura semántica local & $\begin{array}{l}\text { Formas léxicas frecuentes. } \\
\text { Denominación de obxectos e axentes. } \\
\text { Análise dos conceptos e relacións entre conceptos: isotopías. }\end{array}$ \\
& \\
\hline Estruturas sintácticas & Relacións entre as cláusulas. \\
\hline Nivel pragmático & Función comunicativa. \\
\hline
\end{tabular}

Táboa 1: Aspectos analizados 
CAStro, O. / M. LiÑEIRA (eds.) (2015): Trama e urda. Contribucións multidisciplinares desde os estudos galegos, Santiago de Compostela, Consello da Cultura Galega. doi:10.17075/tucmeg.2015.

\section{CORPUS DE ESTUDO}

O corpus escollido está constituído por un total de 21 textos periodísticos publicados nos xornais de maior tirada durante este período (1996-2004), é dicir, El País, ABC e El Mundo. Como fonte principal foi empregado o Corpus de Referencia del Español Actual (CREA). Debe terse en conta que, como se trata nesta presentación de amosar resultados referentes ao galego, non se inclúen no estudo os artigos, moi numerosos, que tratan de xeito illado o éuscaro e o catalán.

No que se refire aos xéneros periodísticos documentados, o corpus inclúe concretamente trece noticias, dez artigos de opinión e unha entrevista. Baixo a etiqueta opinión inclúense os xéneros do artigo de opinión, da crítica, da columna e do editorial. No tocante ao ámbito temático, os textos correspondentes inscríbense nas seguintes categorías: política (7), cultura (6), linguas (3), medios (2), sociedade (2) e historiografía (1).

Hai que ter en conta, con todo, que as fronteiras entre estes ámbitos son ás veces difíciles de establecer, posto que, por exemplo, o desenvolvemento dun tema como o das televisións autonómicas, que se inclúe no grupo de medios, adquire unha dimensión claramente política (vid. anexo 1b: «Viento privatizador en las TV autonómicas», El Mundo, 10/05/1996). Cómpre sinalar, ademais, que a cuestión da(s) lingua(s) nos textos que conforman o corpus non ocupa sempre o mesmo lugar na xerarquía temática. É por isto que se distinguen tres categorías diferentes: a) textos nos que o tema das linguas é principal, b) textos nos que o tema das linguas é secundario e c) textos nos que o tema das linguas ten un carácter moi tanxencial (vid. anexo $1 \mathrm{a}, 1 \mathrm{~b}$ e 1c para cada unha das tres cateogorías). Tendo en conta todas estas dimensións (tipo de texto, ámbito temático e xerarquización temática), o noso corpus podería caracterizarse esquematicamente tal e como se mostra na táboa 2:

\begin{tabular}{|c|c|c|c|c|c|c|c|}
\hline & Cuestiór & as linguas & & & & & \\
\hline & Tema pr & ipal & Tema re & ante & & Tema se & ndario \\
\hline & Noticia & Opinión & Noticia & Opinión & Entrevista & Noticia & Opinión \\
\hline Política & 1 & 2 & 1 & 2 & 1 & & \\
\hline Cultura & & & & & & 3 & 3 \\
\hline Lingua & 1 & 2 & & & & & \\
\hline Medios & & & 2 & & & & \\
\hline Sociedade & 1 & & & & & 1 & \\
\hline Historiografía & & & & & & & 1 \\
\hline
\end{tabular}

Táboa 2: Número e caracterización dos textos que conforman o corpus

En base a estes datos, é posible facer xa varias observacións de interese:

- Cando a lingua aparece como tema principal ou relevante na estrutura temática, a meirande parte dos textos refírese ao tema político. 
CAStro, O. / M. LiÑEIRA (eds.) (2015): Trama e urda. Contribucións multidisciplinares desde os estudos galegos, Santiago de Compostela, Consello da Cultura Galega. doi:10.17075/tucmeg.2015.

- No tocante a este ámbito temático, a tipoloxía dos artigos é variada (dúas noticias, tres artigos de opinión, un editorial e unha entrevista).

- Nos artigos de carácter cultural, a lingua aparece como tema secundario.

\section{ANÁLISE}

\subsection{A macroestrutura semántica}

\subsubsection{Temas recorrentes}

En relación coas linguas ibéricas de ámbito autonómico, no corpus detéctanse algúns temas recorrentes:

- En dous textos, as linguas son presentadas como riqueza e patrimonio común:

(1) Si se pierde una lengua, perdemos todos («Premio al trabajo colectivo de la SER desde el 11-M al 14-M», El País, 24/11/2004).

(2) Conocer más de un idioma es riqueza invaluable («Tribuna: Miguel-León Portilla», El País, 22/12/2004).

- Nestes textos, así como nalgúns outros, aparece unha visión positiva do bilingüismo:

(3) Ya entonces el balance de esta revista de literatura y pensamiento [Papeles] podía resumirse en aportaciones tan decisivas para nuestra cultura bajo el franquismo como estas: conexión entre generaciones [...]; enlace con la España peregrina [...]; alianza entre las lenguas de España, con frecuentes colaboraciones en gallego y catalán de las que Cela gustaba dar versiones en castellano («Cela editor», ABC Cultural, 10/05/1996).

(4) En dos puntos principales coincidimos. Uno fue en la necesidad de diseñar cuidadosamente los programas y métodos de educación bilingüe, de suerte que todos puedan acceder al conocimiento de la que es hoy por hoy lingua franca o general en nuestros países e incluso en algún otro como en los Estados Unidos («Tribuna: Miguel-León Portilla», El País, 22/12/2004).

Trátase, no entanto, dun bilingüismo no que se establece unha sorte de xerarquía, unha relación carente de equilibrio, na que, como vemos no exemplo anterior (4), a lingua española é a lingua franca o general. Neste sentido, é moi interesante a afirmación de Lázaro Carreter recollida nunha das noticias analizadas, segundo a cal o español lles cede ás outras linguas ámbitos de uso:

(5) En la actualidad el castellano está «menos favorecido en la docencia», dijo, «por haberse reconocido, con justicia, la cooficialidad de otras lenguas y por ceder ámbitos que 
CAstro, O. / M. LiñEIRA (eds.) (2015): Trama e urda. Contribucións multidisciplinares desde os estudos galegos, Santiago de Compostela, Consello da Cultura Galega. doi:10.17075/tucmeg.2015.

antes eran suyos, entre ellos gran parte del uso» («El bilingüismo es un vaivén, no sólo un ven», El País, 18/06/1997).

- As linguas de ámbito autonómico son caracterizadas explicitamente como carentes de utilidade noutras comunidades:

(6) La obligación de aprender las lenguas de las nacionalidades históricas, que dejan de serles útiles [a los inmigrantes] en cuanto se trasladan de comunidad autónoma («Un manifiesto de especialistas reclama que se regule la enseñanza de lenguas españolas a inmigrantes», El País, 24/11/2004).

- Case como consecuencia lóxica do anterior, maniféstase no discurso a idea de que estas linguas deben estar vencelladas ao ámbito ritual (coñecemento pasivo /uso literario), pero non ao uso cotiá e normalizado:

(7) Son legítimos, son patrióticos, son plausibles los esfuerzos de los Gobiernos regionales [...] por preservar la lengua propia, fomentar su estudio y conocimiento, promover la producción literaria («El embudo lingüístico», ABC Elec., 20/04/1997).

(8) El propósito de esa educación bilingüe debe abarcar [...] el fortalecimiento de las lenguas nativas, hacer posible su conocimiento gramatical y fomentar la creación literaria en ellas («Tribuna: Miguel-León Portilla», El País, 22/12/2004).

- O obxectivo nunca é a normalización. De feito, os impulsos de carácter político en favor das linguas minorizadas son presentados negativamente:

(9) Son legítimos, son patrióticos, son plausibles los esfuerzos de los Gobiernos regionales [...] por preservar la lengua propia, fomentar su estudio y conocimiento, promover la producción literaria [...]. Lo grave es el expeditivo recurso a medidas coactivas o discriminatorias («El embudo lingüístico», $A B C$ Elec., 20/04/1997).

(10) Parece que el pueblo valenciano se inclina mayoritariamente por la diferenciación. Y ante ello, ¿qué diablos hace el Congreso español metiéndose en esa polémica?(«Postales: El valenciano», ABC Elec., 22/05/1997).

(11) Porque si se trata de una cuestión lingüística, que deje a los lingüistas discutir sobre ella y llegar a sus propias conclusiones. Porque cualquier otra cosa sería politizar la cuestión («Postales: El valenciano», ABC Elec., 22/05/1997).

(12) [El rigor de Gabriel Ferrater] nos habla del ejemplo de una justicia moral que nos será imprescindible esgrimir cuando alguien, o nosotros mismos, sienta o sintamos la tentación de redactar leyes en materia lingüística. [...] penalizar y castigar, en nombre de una lengua, quizá sea tan peligroso y cruel como sembrar con espino un lecho amoroso («Política de la lengua», ABC Elec., 26/08/1997). 
CAstro, O. / M. LiÑEIRA (eds.) (2015): Trama e urda. Contribucións multidisciplinares desde os estudos galegos, Santiago de Compostela, Consello da Cultura Galega. doi:10.17075/tucmeg.2015.

\subsubsection{Tópoi}

Emprégase o termo «topos» para designar unha afirmación, de dominio público, presuposta ou implícita, que non precisa de argumentación ningunha porque é asumida pola opinión pública e nunca cuestionada. A análise dos tópoi resulta moi relevante no estudo da construción do texto, posto que permite prescindir da argumentación á hora de apoiar unha determinada postura. Nos exemplos anteriores $(9,10,11$ e 12) está presente un topos frecuente no corpus estudado, desenvolvemento social da lingua pode ser independente das medidas políticas. Outros tópoi presentes no corpus son:

- A Constitución e os Estatutos son principios irrefutables:

(13) Lo grave es ignorar el bilingüismo oficial —que es la solución que se desprende de la interpretación concorde de la Constitución y los estatutos («El embudo lingüístico», ABC Elec., 20/04/1997).

(14) El titular de Administraciones Públicas [Mariano Rajoy] recordó que la Constitución española no impone el deber de conocer las lenguas autonómicas («Rajoy se niega a imponer el bilingüismo a los funcionarios de la Administración Periférica», ABC Elec., 26/06/1997).

(15) La configuración de una lengua propia de una Autonomía como un deber impuesto a los ciudadanos de esa región ha sido calificado expresamente de inconstitucional por el TC (ib.).

- Os e as falantes das linguas distintas do español nas respectivas comunidades autónomas son minorías:

(16) Como todos los empeños artificiales, impulsados por el dogmatismo de una minoría frente a un impulso social que se resiste a acomodarse al lecho de Procusto del nacionalismo lingüístico, aquellos propósitos están condenados al fracaso («El embudo lingüístico», ABC Elec., 20/04/1997).

A este respecto cómpre ter en conta así mesmo o emprego de designacións como lengua minoritaria:

(17) Por la noche, en la gala, Puyal hizo una defensa de las lenguas minoritarias («Premio al trabajo colectivo de la SER desde el 11-M al 14-M», El País, 24/11/2004).

\subsubsection{Selección de información}

A selección de información por parte da persoa autora implica xa unha posición subxectiva con respecto á noticia, posto que se escollen determinados aspectos que se queren subliñar. Un exemplo claro constitúeo a noticia sobre a 
CAstro, O. / M. LiÑEIRA (eds.) (2015): Trama e urda. Contribucións multidisciplinares desde os estudos galegos, Santiago de Compostela, Consello da Cultura Galega. doi:10.17075/tucmeg.2015.

privatización das televisións autonómicas, na que se destaca información específica sobre o gasto público que estas supoñen:

(18) El conjunto de las televisiones autonómicas españolas consumió en 1995 cerca de 55.000 millones de pesetas de dinero público, sin contar con aportaciones extraordinarias y asunciones de deuda por parte de las comunidades. Más del doble de lo que recibió Radiotelevisión Española en ese mismo año en concepto de subvención («Viento privatizador en las TV autonómicas», El Mundo, 10/05/1996).

No texto sobre a concesión do premio Ondas ao xornalista Joaquim Puyal («Premio al trabajo colectivo de la SER desde el 11-M al 14-M», anexo 1b), o mecanismo é o mesmo, aínda que a intención é moi diferente: as declaracións do protagonista son empregadas para presentar as linguas como riqueza cultural común:

(19) «Hablar en una lengua no es ir en contra de nadie, sino a favor de la cultura, de las culturas», afirmó. «Si se pierde una lengua, perdemos todos», añadió, y recibió la estatuilla «en nombre de todos los profesionales que realizan su trabajo hablando lenguas minoritarias» («Premio al trabajo colectivo de la SER desde el 11-M al 14-M», El País, 24/11/2004).

Ademais inclúese ao final unha observación destinada a subliñar (e ratificar) as palabras do xornalista premiado en tanto que se describe a reacción positiva do público: «Su intervención fue largamente aplaudida» (ib.). A inclusión de citas, como se pode ver no exemplo 19, está moi ligada ao proceso de selección da información: escóllense as citas que se introducen, do mesmo xeito que se selecciona a información ofrecida. Estes procesos serven para reforzar unha determinada perspectiva ou para situar determinados aspectos nun primeiro plano e inflúen, polo tanto, na recepción que o público ten dos feitos. Este fenómeno percíbese claramente na selección das citas na noticia sobre o Manifesto de Santander, documento que propón a regulación do ensino de lingua entre o colectivo de inmigrantes. Aínda que no propio manifesto o tema da cooficialidade de diversas linguas en determinadas comunidades é tanxencial, o artigo acaba centrándose nesta cuestión e na súa problemática (vid. tamén exemplo 6). A este respecto, introdúcense ao final as declaracións posteriores dun dos autores do manifesto:

(20) Sánchez-Mesa explicó, no obstante, que el texto es ambiguo en ese punto «para no dejar fuera a colegas catalanes y vascos, que están haciendo trabajos muy importantes. En cualquier caso», añadió, «el debate está abierto» («Un manifiesto de especialistas reclama que se regule la enseñanza de lenguas españolas a inmigrantes», El País, 24/11/2004).

Esta intervención contribúe a presentar as linguas de ámbito autonómico como un problema sen solucións reais. Ao ser integrada ao final do texto, o seu contido cobra relevancia e funciona a xeito de conclusión. No corpus analizado, 
CAstro, O. / M. LiÑEIRA (eds.) (2015): Trama e urda. Contribucións multidisciplinares desde os estudos galegos, Santiago de Compostela, Consello da Cultura Galega. doi:10.17075/tucmeg.2015.

ademais, hai varios exemplos da toma de posición da/do xornalista con respecto ao contido da cita. Este fenómeno maniféstase, por unha banda, na escolla de determinados verba dicendi que presentan o contido transmitido como veraz. Así, no seguinte exemplo (21), co emprego dun verbo como recordar, o artigo subliña o carácter irrefutable da argumentación do ministro no tocante ao seu rexeitamento de establecer as dúas linguas cooficiais como requisito para conseguir un posto de traballo entre o funcionariado:

(21) El titular de Administraciones Públicas recordó que la Constitución española no impone el deber de conocer las lenguas autonómicas («Rajoy se niega a imponer el bilingüismo a los funcionarios de la Administración Periférica», ABC Elec., 26/06/1997).

No exemplo 22, pertencente á noticia sobre o manifesto de regulación do ensino de lingua entre o colectivo de inmigrantes (vid. exemplos 6 e 20), a visión da persoa entrevistada, segundo a cal a diversidade lingüística no estado é un problema no seu eido, é presentada, mediante a introdución do verbo reconocer, como un feito:

(22) El director de los cursos de español para extranjeros de la UIMP, Domingo SánchezMesa [...] reconoció [...]: «Es evidente que hay un problema, porque gran parte de la población migratoria funciona de manera muy móvil» («Un manifiesto de especialistas reclama que se regule la enseñanza de lenguas españolas a inmigrantes», El País, 24/11/2004).

Por outra banda, prodúcese algún caso no que a introdución da cita responde á interpretación da propia persoa que redacta o texto:

(23) Con respecto a su propuesta de federalismo, Fraga criticó implícitamente a Jordi Pujol por mostrarse en contra del «café para todos». Asimismo, afirmó que «todos formamos parte de una nación única que reconoce las autonomías de sus nacionalidades y regiones» («Fraga dice que el «hecho diferencial» no está para discriminar a comunidades», El Mundo, 13/04/1996).).

\subsection{A estrutura semántica local}

\subsubsection{Denominación do obxecto}

No corpus analizado rexístranse diferentes denominacións para as linguas non estatais: lengua propia (de la Autonomía) (en diferentes artigos de opinión do $A B C$ e tamén nos textos de El Mundo), lenguas cooficiales $(A B C)$, lenguas romances españolas $(A B C)$ lenguas autonómicas $(A B C)$, lenguas minoritarias (El País), lenguas españolas (El País), lenguas oficiales del estado (El País), lenguas de las nacionalidades históricas (El País), lenguas diferenciadas (El País), las otras lenguas (El País) e nuestras tres lenguas romances. 
CAStro, O. / M. LiÑEIRA (eds.) (2015): Trama e urda. Contribucións multidisciplinares desde os estudos galegos, Santiago de Compostela, Consello da Cultura Galega. doi:10.17075/tucmeg.2015.

Algunhas destas designacións repercuten no seu carácter supostamente diferencial ou marcado. A esta categoría pertencen as designacións lengua diferenciada, las otras lenguas e lengua propia. A designación de lengua propia correspóndese coa descrición presente nos respectivos Estatutos de Autonomía, pero nos textos periodísticos analizados adquire o sentido de «o outro, o que é diferente»:

(24) vascos, catalanes, gallegos y andaluces se mantienen en defensa de la televisión pública. Los que tienen lengua propia porque defienden su normalización, y los andaluces porque valoran su papel de servicio público («Viento privatizador en las TV autonómicas», El Mundo, 10/05/1996).

(25) La configuración de una lengua propia de una Autonomía como un deber impuesto a los ciudadanos de esa región ha sido calificado expresamente de inconstitucional («Rajoy se niega a imponer el bilingüismo a los funcionarios de la Administración Periférica, $A B C$ Elec., 26/06/1997).

Outro grupo de expresións fan referencia dalgún xeito á restrición, tanto xeográfica coma de uso. No seu carácter restrito xeograficamente inciden as designacións lenguas autonómicas e lenguas de las nacionalidades históricas. Á restrición de uso apuntan as expresións lenguas cooficiales e lenguas minoritarias. É importante resaltar que a designación de cooficialidad, que describe realmente unha relación bilateral, aplícaselles unicamente ás linguas autóctonas, non ao español (vid. exemplo 5).

As designacións máis neutras documéntanse nos textos nos que o tema das linguas é secundario ou moi tanxencial: as designacións lenguas romances españolas («Mar de poesías», ABC Cult., 04/10/1996) e nuestras tres lenguas romances («Quijote y acracia», El País, 22/12/2004) aparecen en cadanseu artigo de crítica literaria, mentres que a expresión lenguas oficiales del estado se documenta nun texto sobre a campaña contra a SIDA emitida nas diferentes linguas («El sida heterosexual es el único que crece en España», El País, 29/10/1997).

A lingua española, pola contra, aparece a miúdo designada simplemente como la lengua, sen ningún tipo de especificación. De aparecer algún tipo de complemento, este redunda no concepto de COMUNIDADE (lengua común, nuestra lengua), de XENERALIDADE (lengua general ou lengua oficial, nunca cooficial), FUNCIONALIDADE e UTILIDADE (lengua franca) e PRESTIXIO LITERARIO (lengua de Cervantes).

\subsubsection{Denominación de axentes}

As citas implican a inclusión dalgún tipo de información sobre o axente, que no noso corpus adoita ser unha persoa recoñecida. No entanto, sobre todo nos 
CAStro, O. / M. LiÑEIRA (eds.) (2015): Trama e urda. Contribucións multidisciplinares desde os estudos galegos, Santiago de Compostela, Consello da Cultura Galega. doi:10.17075/tucmeg.2015.

artigos de opinión, a presenza de citas é pouco frecuente. O que prima nestes casos é o uso da xeneralización:

(26) Como todos los empeños artificiales, impulsados por el dogmatismo de una minoría frente a un impulso social que se resiste a acomodarse al lecho de Procusto del nacionalismo lingüístico, aquellos propósitos están condenados al fracaso («El embudo lingüístico», ABC Elec., 20/04/1997).

(27) En el hombre de la calle, en cambio, el valenciano como entidad propia sigue prevaleciendo («Postales: El valenciano», ABC Elec., 22/05/1997).

(28) Yo he notado que a los portugueses les molesta que se les hable en gallego, sobreentendiendo que su idioma es una derivación de éste («Postales: El valenciano», ABC Elec., 22/05/1997).

(29) En cualquier caso, parece que el pueblo valenciano se inclina mayoritariamente por la diferenciación («Postales: El valenciano», ABC Elec., 22/05/1997).

Este tipo de referencias adscríbense ao que Edelman denomina mythical groups of reference (Menz 1989: 236), isto é, grupos que non son concretos ou están definidos con exactitude, senón que son creados para lexitimizar o punto de vista da prensa. A xeneralización non parece ser un recurso lexítimo unicamente nos artigos de opinión, senón tamén na noticia. Así, ao tratar o debate sobre o establecemento do coñecemento da lingua autóctona como condición para acceder ao funcionariado, na noticia preséntase a situación da seguinte maneira:

(30) La configuración de una lengua propia de una Autonomía como un deber impuesto a los ciudadanos de esa región ha sido calificado expresamente de inconstitucional por el TC («Rajoy se niega a imponer el bilingüismo a los funcionarios de la Administración Periférica», ABC Elec., 26/06/1997).

(31) Rajoy afirmó que la Administración del Estado no puede perseguir el bilingüismo de los empleados que prestan sus servicios en el ámbito de una Comunidad, ya que daría lugar a imponer el dominio de una lengua cooficial como requisito para ocupar cualquier puesto de trabajo en la Autonomía correspondiente ( $i b$.).

Cómpre ter en conta que a situación que lle serve de base a esta noticia atinxe o uso das linguas minorizadas nas institucións públicas e, polo tanto, o ámbito do funcionariado. 
CAStro, O. / M. LiÑEIRA (eds.) (2015): Trama e urda. Contribucións multidisciplinares desde os estudos galegos, Santiago de Compostela, Consello da Cultura Galega. doi:10.17075/tucmeg.2015.

\title{
3.2.3. As isotopías
}

A análise da estrutura semántica local permite establecer diferentes relacións semánticas ou isotopías (vid. u. a. Lötscher 2005: 87-89). En concreto, as linguas están vencelladas aos seguintes campos semánticos:

\author{
ARTIFICIALIDADE: artificio / artificial, construir / \\ construida / construcciones, reinventada.
}

(32) pero si ésta [la lengua] puede ser recuperada y hasta reinventada como en el caso del euskera [...] ¿qué puede impedir que los asturianos se lancen al desarrollo del bable o los extremeños a la práctica del castúo [...]? («Miajón de los castúos», El Mundo, 20/04/1996).

(33) Lo grave es pasar del reconocimiento natural de un «hecho diferencial» al artificio totalitario de construir coactivamente un hecho diferenciador («El embudo lingǘístico», ABC Elec., 20/04/1997).

CONFLITO: amenazar, conflicto, contencioso, debate, defender, discutir / discusión, extremos, guerra (verbal), guerrilla urbana, (vivas) reacciones, reivindicación, violencia.

(34) La violencia continúa, el nivel de apoyo político al terror es muy parecido, y hasta se está incorporando a la «guerrilla urbana» toda una generación de jóvenes que no conoció la dictadura, ni la represión, y cuyos elementos de referencia son educacionales y teóricos, y entre los que el paro, la lengua y la cerrazón de los burócratas de los partidos juegan un papel muy importante («ETA quiere mayoría absoluta», El Mundo, 15/02/1996).

(35) Pero, en el otro extremo, vascos, catalanes, gallegos y andaluces se mantienen en defensa de la televisión pública. Los que tienen lengua propia porque defienden su normalización, y los andaluces porque valoran su papel de servicio público («Viento privatizador en las TV autonómicas», El Mundo, 10/05/1996).

(36) O se repiensa esta idea europea o [el europeo] se enfrentará a «un futuro ya delineado, el de un superestatalismo económico y financiero [...] respecto al cual todas las diversas culturas, lenguas, tradiciones y religiones europeas llegarán a un punto de conflicto, a un sentimiento de repulsión. Y a la larga, esto puede amenazar hasta la actual forma democrática de nuestros Estados» («El europeo sólo se reconoce como tal en relación a los otros», El País, 10/11/1997).

\section{DIFERENCIACIÓN: diferencia / diferenciación / diferenciada / diferenciadora / diferencial / diferente.}

(37) Junto a las reivindicaciones económicas de Cataluña y Euskadi aparece el deseo profundo de identidad nacional, subrayado por el hecho diferencial de la lengua («Miajón de los castúos», El Mundo, 20/04/1996). 
CAStro, O. / M. LiÑEIRA (eds.) (2015): Trama e urda. Contribucións multidisciplinares desde os estudos galegos, Santiago de Compostela, Consello da Cultura Galega. doi:10.17075/tucmeg.2015.

DISCRIMINACIÓN: discriminar / discriminación / (medidas) discriminatorias, quiebra (del principio de igualdad).

(38) La lengua pasa a utilizarse instrumentalmente como un medio utilizado para la discriminación [...], para la quiebra del principio de igualdad de todos ante la ley («El embudo lingüístico», $A B C$ Elec., 20/04/1997).

IMPOSICIÓN: castigar, (medidas) coactivas / coactivamente, deber, dogmatismo, exigir / exigencia, expeditivo, imponer / imposición, obligación, penalizar, requisito, sometida, totalitario.

(39) Lo grave es pasar del reconocimiento natural de un «hecho diferencial» al artificio totalitario de construir coactivamente un hecho diferenciador («El embudo lingüístico», $A B C$ Elec., 20/04/1997).

(40) Rajoy se niega a imponer el bilingüismo a los funcionarios de la Administración periférica («Rajoy se niega a imponer el bilingüismo a los funcionarios de la Administración Periférica», $A B C$ Elec., 26/06/1997).

(41) [El bilingüismo de los empleados que prestan sus servicios en el ámbito de una Comunidad] daría lugar a imponer el dominio de una lengua cooficial como requisito para ocupar cualquier puesto de trabajo $(i b$.).

(42) El Manifiesto de Santander no menciona, sin embargo, la lengua castellana y pasa de puntillas sobre el problema que supone [...] la obligación de aprender las lenguas de las nacionalidades históricas («Un manifiesto de especialistas reclama que se regule la enseñanza de lenguas españolas a inmigrantes», El País, 24/11/2004).

Unicamente nun dos artigos («Historias, historietas e historia», El País, 28/01/1998, vid. anexo 1c), o concepto de IMPOSICIÓN deixa de estar vencellado ás linguas minorizadas e aos movementos que procuran a súa normalización. Neste caso, pola contra, son as linguas das nacionalidades históricas as que se ven afectadas pola imposición dunha certa visión castellanista:

(43) El nacionalismo tardío de la generación del 98 [...] imponía su visión castellanista a las demás nacionalidades históricas y regiones administrativas, esto es, la disolución de su historia, cultura y lenguas en el aguachirle de la retórica casticista de Ganivet, Unamuno, Maeztu, García Morente et alii. («Historias, historietas e historia», El País, 28/01/1998).

\section{PROBLEMA: problema.}

(44) El portavoz de CiU Joaquín Ferrer resaltó que el «problema» no viene derivado de la gestión del Gobierno del PP, sino de anteriores Ejecutivos socialistas y pidió un mayor esfuerzo para continuar impulsando el proceso de normalización lingüística («Rajoy se 
CAStro, O. / M. LiÑEIRA (eds.) (2015): Trama e urda. Contribucións multidisciplinares desde os estudos galegos, Santiago de Compostela, Consello da Cultura Galega. doi:10.17075/tucmeg.2015.

niega a imponer el bilingüismo a los funcionarios de la Administración Periférica», $A B C$ Elec., 26/06/1997).

(45) El Manifiesto de Santander no menciona, sin embargo, la lengua castellana y pasa de puntillas sobre el problema que supone, para una colectivo de tanta movilidad geográfica como los inmigrantes, la obligación de aprender las lenguas de las nacionalidades históricas («Un manifiesto de especialistas reclama que se regule la enseñanza de lenguas españolas a inmigrantes», El País, 24/11/2004).

(46) Cuestión íntimamente relacionada con la anterior fue preguntarse si tal realidad [la diversidad lingüística en los territorios hispanohablantes] constituye un problema o una riqueza («Tribuna: Miguel-León Portilla», El País, 22/12/2004).

Algunhas das formas pertencentes aos campos semánticos mencionados están empregadas nun sentido metafórico ou integradas a través dun símil:

(47) Se resiste a acomodarse al lecho de Procusto del nacionalismo lingüístico («El embudo lingüístico», $A B C$ Elec., 20/04/1997).

(48) [El rigor de Gabriel Ferrater] nos habla del ejemplo de una justicia moral que nos será imprescindible esgrimir cuando alguien, o nosotros mismos, sienta o sintamos la tentación de redactar leyes en materia lingüística («Política de la lengua», $A B C$ Elec., 26/08/1997).

(49) penalizar y castigar, en nombre de una lengua, quizá sea tan peligroso y cruel como sembrar con espino un lecho amoroso $(i b$.$) .$

Estes recursos estilísticos cumpren unha dobre función: por unha banda, dirixen a atención do público cara ao concepto que se quere transmitir (ARTIFICIALIDADE, CONFLITO, IMPOSICIÓN), de xeito que sexa máis doada a súa captación e a súa memorización; pola outra, crean un vencello emocional co público ao procurar a simpatía do mesmo cara á mensaxe ou á persoa emisora.

\subsection{Estruturas sintácticas}

O uso de recursos estilísticos percíbese tamén no plano sintáctico. Mediante a repetición de estruturas sintácticas (vid. exemplo 50) e da súa dislocación (vid. exemplo 51), conséguese nun dos artigos de opinión analizados, no que se contrapoñen dúas perspectivas diferentes de entender a política lingüística, subliñar o carácter negativo dunha destas posturas, en concreto, a máis comprometida coa lingua autóctona. No primeiro caso, a estrutura lo grave 
CAStro, O. / M. LiÑEIRA (eds.) (2015): Trama e urda. Contribucións multidisciplinares desde os estudos galegos, Santiago de Compostela, Consello da Cultura Galega. doi:10.17075/tucmeg.2015.

encabeza diferentes oracións coas que se describen determinadas actitudes atribuídas á política lingüística correspondente:

(50) Lo grave es el expeditivo recurso a medidas coactivas o discriminatorias. Lo grave es el olvido de que el español es [...] tan «lengua propia» de Cataluña, Valencia, Galicia o el País Vasco como puedan serlo el catalán, valenciano, gallego y euskera respectivamente.

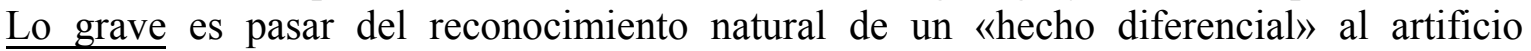
totalitario de construir coactivamente un hecho diferenciador. Lo grave es ignorar el bilingüismo oficial («El embudo lingüístico», ABC Elec., 20/04/1997).

No segundo, colócase a expresión bien está, claramente valorativa, ao final da oración, nun lugar, polo tanto, especialmente relevante:

(51) Mientras estas políticas se mantengan en la acción administrativa de fomento y no pasen al ejercicio de la acción de policía, bien está («El embudo lingüístico», $A B C$ Elec., 20/04/1997).

A interrupción da cadea oracional, marcada pola introdución de determinados signos de puntuación, tamén contribúe en diversos textos a resaltar determinados contidos, como se pode observar nos exemplos 52 e 53:

(52) El conjunto de las televisiones autonómicas españolas consumió en 1995 cerca de 55.000 millones de pesetas de dinero público, sin contar con aportaciones extraordinarias y asunciones de deuda por parte de las comunidades. Más del doble de lo que recibió Radiotelevisión Española en ese mismo año en concepto de subvención («Viento privatizador en las TV autonómicas», El Mundo, 10/05/1996).

(53) Ya no discutían porque entre sí habían agotado todos los argumentos. Siendo todos válidos. E igualmente convincentes («Postales: el valenciano», ABC Elec., 22/05/1997).

Outra estratexia retórica de carácter sintáctico destinada a chamar a atención sobre unha determinada mensaxe e facilitar a súa retención é a introdución do modo interrogativo, a través do que as persoas receptoras se senten interpeladas:

(54) ¿Qué puede impedir que los asturianos se lancen al desarrollo del bable o los extremeños a la práctica del castúo, que tiene mucho de castellano antiguo y popular? («Miajón de los castúos», El Mundo, 20/04/1996).

De xeito menos explícito ca as formas léxicas, a activación destes recursos sintácticos contribúe a subliñar ideas como IMPOSICIÓN (50, 51), PROBLEMA (52), CONFLITO (53) e DIFERENCIACIÓN (54), campos semánticos que conforman o discurso (vid. § 3.2.3). 
CAstro, O. / M. LiÑEIRA (eds.) (2015): Trama e urda. Contribucións multidisciplinares desde os estudos galegos, Santiago de Compostela, Consello da Cultura Galega. doi:10.17075/tucmeg.2015.

\subsection{Nivel pragmático}

Característica da linguaxe xornalística é a presentación dos contidos dun xeito asertivo. Esta aserción, no entanto, pode materializarse de diferentes maneiras: 1) a través da presentación de feitos ou 2) mediante a introdución de elementos valorativos, técnica característica dos artigos de opinión, colaboración e editoriais. No noso corpus detéctase esta segunda posibilidade tamén nas noticias, en concreto:

- No emprego de determinados verba dicendi que implican valoración con respecto ao que se afirma na cita (como reconocer e recordar, vid. exemplos 21 e 22).

- Na interpretación (ou inferencia) por parte da persoa autora do texto das declaracións das figuras protagonistas (vid. exemplo 23).

No que se refire á presentación dos contidos, a inclusión de determinada información implica un proceso de selección que non deixa de ser subxectivo. No corpus analizado, esta información contribúe a enfocar o tema cara a un certo conflito (mobilidade dos inmigrantes, falta de consenso con respecto ás linguas, gasto público, etc.). Ademais, destaca nas noticias a presenza de citas (resultado tamén da selección de información e mesmo interpretadas subxectivamente, como se aprecia nos exemplos 19-23) así como a utilización de certos tópoi ou afirmacións comunmente aceptadas que, polo tanto, non requiren argumentación (§ 3.1.2). Nas referencias ao tema da lingua, por último, empréganse diversos recursos expresivos, orientados sobre todo a chamar a atención da persoa receptora sobre a propia mensaxe.

Todos estes elementos presentes na aserción desempeñan unha función persuasiva (van Dijk 1990: 124-128) que implica 1) introducir elementos, como citas e datos concretos, para convencer ao público da veracidade dos feitos, 2) chamar a súa atención sobre determinados contidos e 3) crear un vínculo emocional coa mensaxe ou coa propia entidade autorial. A intención última é transmitir determinadas mensaxes e convencer ao público da súa validez.

Partindo das dimensións tradicionais da retórica (docere, movere e delectare), no corpus estudado predomina claramente a segunda dimensión, orientada a espertar certas emocións no público e propiciar que asuma, deste xeito, unha determinada perspectiva.

\section{CONCLUSIÓNS}

A cuestión da diversidade lingüística no estado español é tratada na prensa, sobre todo, en relación coa política. De feito, un terzo dos textos que conforman o corpus adcríbese claramente a este eido macrotemático. Nos artigos 
CAStro, O. / M. LiÑEIRA (eds.) (2015): Trama e urda. Contribucións multidisciplinares desde os estudos galegos, Santiago de Compostela, Consello da Cultura Galega. doi:10.17075/tucmeg.2015.

enmarcados no ámbito cultural, a presenza das linguas non estatais limítase case sempre á súa mención.

Con respecto ao xénero, o corpus está conformado tanto de noticias (12) coma de textos pertencentes ao xénero da opinión (10) e dunha entrevista (1). Con todo, tamén nas noticias está presente a función persuasiva orientada conmover o público. Esta función maniféstase lingüisticamente no emprego de elementos valorativos e interpretativos, tópoi e recursos estilísticos.

$\mathrm{O}$ concepto de lingua cooficial está vencellado con frecuencia ao ámbito semántico de DIFERENCIACIÓN, CONFLITO, PROBLEMA, ARTIFICIALIDADE e IMPOSICIÓN. Estes conceptos están interrelacionados e forman parte, polo tanto, dun mesmo discurso. A situación das linguas minorizadas, marcadas como «algo que é distinto», «que é restrito» (sobre todo a través das diferentes denominacións, pero tamén a través de determinadas escollas léxicas, como hecho diferencial e carácter diferenciador), depende do labor político. Este, pola súa banda, é presentado no discurso como un labor de imposición e mesmo valorado de xeito explícito como algo grave. O concepto de ARTIFICIALIDADE atopa o seu lugar nesta liña de pensamento: se a normalización dunha lingua depende dos esforzos políticos e, polo tanto, de esforzos alleos á súa propia natureza é, xa que logo, artificial. Estanse a introducir e perpetuar esquemas que poderían ser rebatidos, posto que tamén as linguas hexemónicas o son en virtude dunha acción política normalizadora e normativa. Por último, as linguas, non as respectivas vías políticas, son presentadas como problema ou motivo de conflito.

Por outra banda, as linguas están vinculadas ao concepto de RIQUEZA (vid. exemplos 1 e 2). Neste tipo de discurso, paralelo ao anterior, mantense unha visión da lingua como ben precioso, pero non se menciona a súa validez comunicativa ou se tratan as posibles vías da normalización. De feito, é a lingua española a que será caracterizada neste discurso como lengua común, franca e general (vid. exemplo 4, así como $§ 3.2 .1$.).

Un terceiro discurso apréciase no artigo «Historias, historietas e historia» (El País, 28/01/1998, vid. anexo 1c), no que as linguas das nacionalidades históricas son presentadas, xunto coa historia e a cultura, como elementos afectados por una determinada visión castelanista (vid. exemplo 43).

No que respecta ao discurso maioritario, detéctase a polarización característica dos discursos marcados ideoloxicamente (van Dijk 2003). Esta polarización contribúe a crear unha barreira entre o grupo de opinión no que se adscribe a persoa emisora e o outro grupo. No noso corpus maniféstase este fenómeno por medio de diferentes recursos:

- Construción de campos semánticos contrapostos: USO RITUAL / UTILIDADE, MAIORÍA / MINORÍA, RESTRICIÓN DE USO / XENERALIDADE, RESTRICIÓN XEOGRÁFICA / COMUNIDADE 
CAstro, O. / M. LiÑEIRA (eds.) (2015): Trama e urda. Contribucións multidisciplinares desde os estudos galegos, Santiago de Compostela, Consello da Cultura Galega. doi:10.17075/tucmeg.2015.

- Campos semánticos negativos que atinxen as linguas minorizadas: PROBLEMA, CONFLITO, ARTIFICIALIDADE, IMPOSICIÓN, VIOLENCIA.

- Xeneralización e construción, con respecto aos axentes, de grupos «míticos de referencia».

Nos textos xornalísticos acerca das linguas presentes na prensa española durante este período é posible identificar e sistematizar, xa que logo, as características propias dun discurso de carácter claramente ideolóxico: a polarización, a ausencia de argumentación, o intento de establecer un contacto emocional co público e a primacía dunha función asertiva persuasiva. Neles pode distinguirse unha liña maioritaria na que a lingua minorizada é presentada como base de conflito e outra, minoritaria, que a caracteriza como riqueza e patrimonio a protexer.

Con respecto á tendencia discursiva maioritaria neste período, é posible falar mesmo da creación e divulgación de valores discriminatorios que inciden directamente na representación das linguas e, indirectamente, as persoas que as falan. Se o ideal é un tipo de bilingüismo no cal a lingua española desempeñe unha función hexemónica, mentres que a lingua autóctona queda relegada a un uso ritual e literario (como tesouro e patrimonio) e é caracterizada como problema, factor de diferenciación e diferencialismo ou mesmo base de conflito, daquela cómpre preguntar: como serán logo conceptuadas as persoas que, de xeito voluntario e consciente, escollen ser falantes desta lingua?

\section{REFERENCIAS BIBLIOGRÁFICAS}

BUSSE, Dietrich / Wolfgang TEUBERT (1994): «Ist Diskurs ein sprachwissenschaftliches Objekt?», en BUSSE, Dietrich / Fritz HERMANNS / Wolfgang TEUBERT (eds.): Begriffsgeschichte und Diskursgeschichte. Methodenfragen und Forschungsergebnisse der historischen Semantik, Opladen, Westdeutscher Verlag, 10-28.

FAIRCLOUGH, Norman (1993): «Critical Discourse Analysis and the Marketization of Public Discourse: the Universities», Discourse \& Society, 4, 133-168.

LÖTSCHER, Andreas (2005): «Textsemantische Ansätze», en Nina JANICH: Textlinguistik. 15 Einführungen, Tübingen, Narr, 85-111.

MARTÍN SERRANO, Manuel (2004 [1986, 1993]): La producción social de comunicación, Madrid, Alianza.

MENZ, Florian (1989): «Manipulation strategies in newspapers: a program for critical linguistics», en Ruth WODAK (ed.): Language, Power and Ideology, Amsterdam / Philadelphia, John Benjamin, 227-249.

SPIEß, Constanze (2008): «Linguistische Diskursanalyse als Mehrebenenanalyse - Ein Vorschlag zur mehrdimensionalen Beschreibung von Diskursen aus forschungspraktischer Perspektive», en Ingo H. WARNKE / Jürgen SPITZMÜLLER 
CAStro, O. / M. LiÑEIRA (eds.) (2015): Trama e urda. Contribucións multidisciplinares desde os estudos galegos, Santiago de Compostela, Consello da Cultura Galega. doi:10.17075/tucmeg.2015.

(eds.): Methoden der Diskurslinguistik. Sprachwissenschaftliche Zugänge zur transtextuellen Ebene, Berlin / New York, de Gruyter, 237-262.

TITSCHER, Stefan / Michael MEYER / Ruth WODAK / Eva VETTER (2000): Methods of Text and Discourse Analysis, London, Sage.

VAN DIJK, Teun A. (1987): «Mediating racism. The role of the media in the reproduction of racism», en Ruth WODAK (ed.): Language, Power and Ideology, Amsterdam, Benjamins, 199-226.

VAN DIJK, Teun A. (1990): La noticia como discurso. Comprensión, estructura y producción de la información, Barcelona, Paidós Ibérica.

VAN DIJK, Teun A. (1993): «Principles of Critical Discourse Analysis», Discourse \& Society, 4, 249-283.

VAN DIJK, Teun A. (2003): Ideología y discurso. Madrid: Ariel.

WARNKE, Ingo H. / Jürgen SPITZMÜLLER (2008): «Methoden und Methodologie der Diskurslinguistik - Grundlagen und Verfahren einer Sprachwissenschaft jenseits textueller Grenze», en Ingo H. WARNKE / Jürgen SPITZMÜLLER (eds.): Methoden der Diskurslinguistik. Sprachwissenschaftliche Zugänge zur transtextuellen Ebene, Berlin / New York, de Gruyter, 3-45.

\section{FONTES:}

REAL ACADEMIA ESPAÑOLA: Banco de datos (CREA) [en liña]. Corpus de referencia del español actual. $<\mathrm{http}: / / \mathrm{www}$. rae.es $>$ [12.08.2012]

$<$ http://documenta.elmundo.orbyt.es $>$ [11.12.2012]

$<\mathrm{http}: / /$ hemeroteca.abc.es $>$ [11.12.2012]

$<$ http://elpais.com/diario $>$ [11.12.2012] 
CAStro, O. / M. LiÑEIRA (eds.) (2015): Trama e urda. Contribucións multidisciplinares desde os estudos galegos, Santiago de Compostela, Consello da Cultura Galega. doi:10.17075/tucmeg.2015.

\section{ANEXO}

\section{Anexo 1: Artigos analizados distribuídos segundo a relevancia que adquire o tema das linguas na estrutura temática}

a) Textos nos que o tema das linguas é principal:

«El embudo lingüístico», $A B C, 20 / 04 / 1997$. Editorial no que se expresa a perspectiva do xornal no que respecta á pluralidade lingüística do estado español e ás políticas lingüísticas das nacionalidades históricas.

«Postales: El valenciano», $A B C, 22 / 05 / 1997$. Artigo de opinión de José María Carrascal incluído na súa columna «Postales». Trata sobre a cuestión do valenciano e defende a súa definición como lingua diferenciada do catalán en tanto que compara a relación entre estas dúas variedades coa que existe entre galego e portugués.

«Rajoy se niega a imponer el bilingüismo a los funcionarios de la Administración», $A B C, 26 / 06 / 1997$. Noticia sobre as declaracións do daquela ministro de Administración Públicas, Mariano Rajoy, e o seu rexeitamento a calquera proposta parlamentaria para regular o uso da lingua minorizada na administración das rexións con máis dunha lingua oficial.

«El bilingüismo es un vaivén, no sólo un ven», El País, 18/06/1997. Noticia sobre a conferencia de Lázaro Carreter «El español y sus retos de futuro», ofrecida no Centro Cultural del Círculo de Lectores de Madrid co gallo do ciclo Nuevas visiones de España. O autor defende como ideal o establecemento do bilingüismo nas comunidades con dúas linguas oficiais.

«Política de la lengua», ABC Elec., 26/08/1997. Artigo de opinión de Juan Pedro Quiñonero no que se describe a traxectoria do poeta catalán Gabriel Ferrater. Este contexto é aproveitado polo autor do artigo para facer unha reflexión sobre o bilingüismo e a política lingüística nas comunidades con máis dunha lingua oficial.

«Un manifiesto de especialistas reclama que se regule la enseñanza de lenguas españolas a inmigrantes», El País, 24/11/2004. Noticia sobre o denominado Manifesto de Santander, asinado por especialistas no ensino de lingua co que se tenta regular o ensino das linguas entre o colectivo de inmigrantes. $\mathrm{O}$ manifesto inclúe as linguas cooficiais de xeito tanxencial, pero iguálaas ao español. No artigo é precisamente a cuestión (supostamente problemática) de conxugar as dúas linguas a que acaba acadando relevancia na xerarquía temática. 
CAStro, O. / M. LiñEIRA (eds.) (2015): Trama e urda. Contribucións multidisciplinares desde os estudos galegos, Santiago de Compostela, Consello da Cultura Galega. doi:10.17075/tucmeg.2015.

«III Congreso de la Lengua Española en Rosario», El País, 22/12/2004. Artigo de colaboración de Miguel León Portilla no que se presentan as conclusión do III Congreso de la lengua española celebrado en Rosario. Tema central do congreso foi a consideración do español como lingua común e o reto que presenta, sobre esta base, manter e respectar a diversidade lingüística nos estados que teñen o español como lingua oficial.

b) Textos nos que o tema das linguas adquire unha posición importante na estrutura temática, aínda que non principal:

«ETA quiere mayoría absoluta», El Mundo, 15/02/1996. Artigo de opinión de Raúl Heras publicado o día despois do asasinato do xurista Tomás y Valiente por parte de ETA. Entre os factores que están na base das reivindicacións dos grupos violentos sinálase a lingua.

«Fraga dice que el "hecho diferencial" no está para discriminar a comunidades», El Mundo, 13/04/1996. A noticia céntrase nas declaracións de Fraga acerca de diferentes puntos: 1) o acordo político entre PP e Coalición Canaria, 2) o posible acordo do PP galego con CiU, 3) os acordos financiación autonómica e fiscalidade e 4) o federalismo e o chamado «feito diferencial». É neste cuarto punto onde o tema da lingua cobra especial relevancia. A lingua está ademais mencionada na propia entrada do artigo: «El presidente de la Xunta de Galicia, Manuel Fraga, aseguró ayer que sólo se debe entender el hecho diferencial a los efectos de la lengua y de la cultura».

«El miajón de los castúos», El Mundo, 20/04/1996. Artigo de opinión de Raúl Heras sobre o político extremeño Juan Ignacio Barrero, líder do PP en Extremadura e nomeado presidente do Senado cando Aznar chega ao poder. O artigo mantén un ton irónico e caracteriza a Barrero como representante dunha sorte de nacionalismo extremeño e como defensor da variedade lingüística da comunidade, tamén denominada castúo. Este tema é aproveitado polo autor para facer unha digresión sobre as linguas das nacionalidades históricas.

«Viento privatizador en las TV autonómicas», El Mundo, 10/05/1996. Noticia sobre o proceso de privatización das televisións autonómicas. Un dos factores que provocan a resistencia de determinados gobernos autonómicos á privatización é a consideración de que é necesario preservar este tipo de medios como espazos reservados á lingua autóctona.

«El europeo sólo se reconoce como tal en relación a los otros», El País, 10/11/1997. Entrevista ao filósofo italiano Massimo Cacciari, daquela alcalde de Venecia. A conversa céntrase no concepto de Comunidade Europea e a ausencia dunha reflexión profunda sobre as súas consecuencias políticas e culturais. $\mathrm{O}$ filósofo advirte do perigo de pasar por alto as diferenzas culturais e lingüísticas. 
CAstro, O. / M. LiÑEIRA (eds.) (2015): Trama e urda. Contribucións multidisciplinares desde os estudos galegos, Santiago de Compostela, Consello da Cultura Galega. doi:10.17075/tucmeg.2015.

«Premio al trabajo colectivo de la SER desde el 11-M al 14-M», El Pais, 24/11/2004. Noticia sobre a concesión do Premio Ondas ao xornalista catalán Joaquim Puyal. A noticia céntrase na súa traxectoria profesional, pero tamén no alegato en favor das linguas minoritarias que o xornalista premiado levou a cabo durante a cerimonia.

c) Textos nos que a cuestión das linguas aparece só de xeito tanxencial:

«Cela editor», $A B C, 10 / 05 / 1996$. Artigo homenaxe de Darío Villanueva a Camilo José Cela no que se menciona o seu labor como editor da revista Papeles, espazo cultural aberto a colaboracións literarias en varias linguas peninsulares.

«La edición de libros en castellano descendió en un 3,5\% en 1995 », El Mundo, 30/05/1996. Informe sobre os índices de publicación en cada unha das linguas do estado.

«Mar de poesías», $A B C, 04 / 10 / 1996$. Noticia sobre a publicación dunha antoloxía de 7.000 poemas nas diferentes linguas romances españolas.

«Hoy se fallarán las nominaciones para los Premios Goya», El Mundo, 27/12/1996.

«Anaya edita en CD-Rom un cuento de Hans Christian Andersen», $A B C$, 14/09/1997. A noticia informa de que o conto foi editado nas diferentes linguas.

«El sida heterosexual es el único que crece en España y se sitúa a la cabeza de Europa», El País, 29/10/1997. Noticia sobre a campaña para a prevención da SIDA, publicada «en todas las lenguas oficiales del Estado».

«Historias, historietas e historia», El País, 28/01/1998. Artigo de opinión escrito por Juan Goytisolo, que, partindo da historiografía, se converte nun alegato a favor dunha revisión da historia da Península Ibérica evitando a ideoloxización.

«Quijote y acracia», El País, 22/12/2004. Artigo de Eduardo Haro Tecglen, no que define a Cervantes utilizando o adxectivo ácrata, "palabra que es relativamente nueva en nuestras tres lenguas romances». 